\title{
The genetic component of the forced diving bradycardia response in mammals
}

\author{
Andreas Fahlman ${ }^{1}$, Brian L. Bostrom ${ }^{2}$, Kiran H. Dillon ${ }^{2}$ and David R. Jones ${ }^{2 \dagger}$ \\ ${ }^{1}$ Department of Life Sciences, Texas A\&M University - Corpus Christi, Corpus Christi, TX, USA \\ 2 Department of Zoology, The University of British Columbia, Vancouver, BC, Canada
}

Edited by:

Rita S. Mehta, University of California Santa Cruz, USA

\section{Reviewed by:}

Dan Crocker, Sonoma State, USA Melinda Fowler, University of

California Santa Cruz, USA

${ }^{*}$ Correspondence:

Andreas Fahlman, Texas A\&M University - Corpus Christi, 6300

Ocean Drive, Unit 5800, Corpus

Christi, TX 78412, USA.

e-mail: andreas.fahlman@tamucc.edu

${ }^{+}$Deceased November 19, 2010
We contrasted the forced diving bradycardia between two genetically similar (inbred) rat strains (Fischer and Buffalo), compared to that of outbred rats (Wistar). The animals were habituated to forced diving for 4 weeks. Each animal was then tested during one $40 \mathrm{~s}$ dive on each of 3 days. The heart rate $\left(\mathrm{f}_{\mathrm{H}}\right)$ was measured before, during, and after each dive. Fischer and Buffalo exhibited marked difference in dive bradycardia (Fischer: $120.9 \pm 14.0$ beats min $^{-1}$ vs. Buffalo: $92.8 \pm 12.8$ beats min $\left.^{-1}, P<0.05\right)$. Outbred rats showed an intermediate response $\left(103.0 \pm 30.9\right.$ beats $\left.\mathrm{min}^{-1}\right)$ but their between-animal variability in mean dive $f_{H}$ and pre-diving resting $f_{H}$ were higher than the inbred strains $(P<0.05)$, which showed no difference $(P>0.05)$. The decreased variability in $f_{H}$ in inbred rats as compared with the outbred group indicates that reduced genetic variability minimizes variability of the diving bradycardia between individuals. Heritability within strains was assessed by the repeatability $(R)$ index and was $0.93 \pm 0.05$ for the outbred, $0.84 \pm 0.16$ for Buffalo, and $0.80 \pm 0.12$ for Fischer rats for $f_{\mathrm{H}}$ during diving. Our results suggest that a portion of the mammalian diving bradycardia may be a heritable trait.

Keywords: forced diving, heart rate, rat, repeatability, quantitative genetics

\section{INTRODUCTION}

The heart and brain are organs that are vitally dependent upon a continuous supply of oxygen. Interruption of oxygen supply for only a short time, as occurs during sleep apnea, stroke, or heart disease, can cause permanent damage or death. Scholander (1963) coined the phrase "master switch of life" to describe the cardiovascular role of the diving response (bradycardia and reduced peripheral blood flow) in reducing the demand for oxygen in both forced and free-diving vertebrates. It has been suggested that the mammalian dive response is a conserved physiological trait that arises from natural selection, reflecting genotypic adaptations to prolonged apnea or asphyxia. The response is observed in both aquatic (Butler and Jones, 1997), and semi-aquatic (rat and musk rat; Signore and Jones, 1995, 1996; Mcculloch et al., 2010a; Panneton et al., 2010a,b) mammals, preventing permanent damage of heart and brain during prolonged apnea. Even fish show bradycardia when removed from water, raising the question whether bradycardia is a pre-adaptation to hypoxia or asphyxia (Davis et al., 2004) or an evolved adaptation driven by selection across evolutionary time (Scholander, 1963).

A similar, although less prominent, type of response also occurs in man (Lindholm et al., 1999), making studies on appropriate animal models particularly relevant to humans. The fact that the diving response in individual humans is repeatable over many years suggests heritability (Terblanche et al., 2004), and such heritability is widely assumed, but has never been directly demonstrated. Previous studies have shown great variability in the human diving bradycardia, and individual factors such as age and diving experience have been suggested to modify the response (Lin and Baker, 1975; Manley, 1990). It is known that several factors induce or modify these cardiovascular responses, such as arterial hypoxia and hypercapnia, cessation of respiratory movements, and face immersion (Butler and Jones, 1997; Lindholm et al., 1999). Even though the physiological mechanism of this response has been thoroughly investigated (Butler and Jones, 1997; Lundgren and Miller, 1999), we are not aware of any study that has investigated the genetic basis of this physiological trait.

Simple physiological traits that are regulated by a single gene represent only a small portion of the total genetic makeup of any organism. Most phenotypes are complex and involve interactions between many genes and environmental factors. This complicates the use of physiological traits as indicators of heritability as it is difficult to tease apart environmental from genetic variation. Reducing the genetic variation between animals is one potential strategy for dealing with complex traits. Inbred rat strains are the product of 20 or more generations of brother-sister matings, making individuals within a strain genetically identical and homozygous at most loci. This assures reduced genetic variability within strains. Therefore, any difference in a physiological variable between strains assures that a portion of the trait is genetically encoded and facilitates isolation of the genetic basis of the phenotype (Tankersley et al., 1994, 1997). Rats are an excellent animal model to study the genetic component of the heart rate responses during diving as inbred strains are readily available. In addition, several studies have concluded that they are a good research model for the dive response as they are semi-aquatic animals that are easily trained, they possess a strong diving bradycardia response during forced as well as voluntary dives (Ollenberger et al., 1998; Mcculloch et al., 2010a; Panneton et al., 2010a), and are able to 
dive for as long as $60-80 \mathrm{~s}$ in $30^{\circ} \mathrm{C}$ water (Lin and Baker, 1975; Panneton et al., 2010a).

In this study, we isolated two different inbred strains with varying heart rate responses to forced diving and compared these against an outbred strain (wild type). The data from the various strains allowed us to determine (1) what proportion of the overall variability is genetic and if (2) the mammalian diving bradycardia is heritable.

\section{MATERIALS AND METHODS}

All animal and experimental protocols were reviewed and approved by the Animal Care Committee of University of British Columbia.

\section{ASSUMPTIONS}

Inbred rat strains are the product of 20 or more generations of brother-sister matings, making individuals within a strain genetically identical and homozygous at most loci (Haldane and Waddington, 1931). Consequently, inbred strains as a model to study heritable effects of physiological traits offer unique advantages because (1) the magnitude of genetic variability can be controlled, (2) environmental factors can be strictly controlled in a laboratory setting, and (3) variation between strains in the trait considered can be partitioned into its genetic and environmental components.

\section{ANIMALS}

Male inbred rats from the following strains were purchased from Charles River Laboratories, Inc. (Wilmington, MA, USA): Fischer $344(F)$, and Buffalo $(B)$. The choice of strains was made by the limited knowledge of their physiological phenotypes. Fischer F344 is a very common all-purpose strain and a large literature base exists for this strain, our "control" strain. The Buffalo strain has compromised thyroid function affecting metabolic rate. One strain of outbred Wistar rats (W), bred at the Animal care facility at UBC (UBC Animal Care Centre, Rodent breeding unit, original stock from Charles River), was also examined. The rats of the outbred strain were not crossed with their siblings and variation in the heart rate response during diving from this strain includes both genetic and environmental variation.

All animals were recently weaned pups (3-5 weeks old, $\sim 30$ $35 \mathrm{~g}$ ), examined on receipt by the veterinary staff and housed in the animal care facility. After arrival, the rats were stabilized for 4 days, and held at $22.0 \pm 0.5^{\circ} \mathrm{C}$ at $60 \%$ relative humidity under a $12-\mathrm{h}$ light/dark cycle with ad libitum access to standard rat chow (Lab diet 5001, Rodent diet PMI nutrition Int., Brentwood, MO, USA) and water. The ambient room temperature during manipulations, i.e., training, surgery, dive experiments, was controlled around $20^{\circ} \mathrm{C}$, but the humidity was not altered. While some studies have indicated that this air temperature is below that corresponding to minimum metabolic effort (Gordon et al., 1991), our housing complied with the National Institutes of Health guidelines for the care and use of laboratory animals. In addition, previous studies in rats have used a similar housing temperature and report normal blood pressure and heart rate values (Mcculloch et al., 2010b; Panneton et al., 2010a).

\section{TRAINING}

To reduce stress from forced submersions, the rats were progressively habituated to water immersion. Five days a week (Mon-Fri) each animal performed a training session in the morning and another in the afternoon. During the first week, the rats were placed in a bucket filled with water. Initially, the water level allowed the animals to stand on the bottom and the water level was raised during repeated sessions. When the water level was deep enough so that the animals could not stand on the bottom, they swam around searching for an exit point. Most rats began to dive voluntarily after about the third training session.

After the first week of water habituation, the rats began forced dive training. The animal was placed in a restraining device. The restrainer was varied in size as the rats grew to minimize movement. Each training session involved three repeated submersions separated by at least $5 \mathrm{~min}$. Initial submersions were $<5 \mathrm{~s}$ in duration. The duration of submergence was increased on a daily basis based on the comfort level of the rat to a maximum dive duration of $40 \mathrm{~s}$. Once rats dived for $40 \mathrm{~s}$, they were prepared for experimental trials by implanting subcutaneous ECG electrodes. The dive duration was limited at $40 \mathrm{~s}$ for all strains to reduce variation between individuals and strains. This duration appeared to be tolerated by the inbred strains during initial trials and is well within the maximum reported dive duration for rats of similar size (Panneton et al., 2010a,b).

\section{SURGICAL PROCEDURE AND HEART RATE MEASUREMENTS}

Heart rate was measured by surgically implanting two ECG electrode wires. Rats were prepared for surgery by placing the animal in a pre-anesthetization box flushed with isoflurane. Once unconscious, the animal was removed from the box and the head placed in a modified head cone to which anesthetic gas was delivered in $\mathrm{O}_{2}$. The amount of isoflurane delivered was initially $\sim 3-4 \%$ isoflurane. When the rat reached a surgical plane of anesthesia (i.e., no pinch reflex or response to pain,) the isoflurane concentration was adjusted as necessary ( $1-2.5 \%$ isoflurane). Once properly anesthetized, analgesia (Ketoprofen, $2 \mathrm{mg} \mathrm{kg}^{-1}$ ) was administered intramuscularly. Betadine was used to cold sterilize all instruments and the ECG electrodes. The incision sites were shaved and disinfected using betadine.

Using aseptic techniques, dorsal incisions were made on either side of the vertebral column. The electrodes were implanted subcutaneously on the ventral side of the animal, one on each side of the sternum. The wires were made of stainless steel with a silicone sleeve, leaving only the wire tips bare. The opposite ends of the ECG electrode wires were inserted into a $21 \mathrm{G}$ needle which in turn was tunnelized subcutaneously to a third incision about $2 \mathrm{~cm}$ from the base of the head. The needle was removed leaving the ends in place. The electrodes were immobilized by fixing the ends subcutaneously using an absorbable suture. The external end of each wire was exposed and attached to the heart rate recorder. The incisions were closed using common suturing techniques. Before removal of the anesthetic gas, the rat received an intramuscular injection of Baytril $\left(2.5 \mathrm{mg} \mathrm{kg}^{-1}\right)$. Following surgery, the animal was observed until it awoke and returned to a solitary enclosure until complete recovery $(\sim 1-2 \mathrm{~h})$ after which the rat was returned to the holding pen. Experiments were 
conducted approximately 5 days after surgery when the rat had finally recovered.

The ECG was measured by connecting the external ends of the implanted electrodes to an amplifier (Gould universal amplifier model 13/4615/58). The amplified ECG signal was passed via a purpose built analog-to-digital converter to a data acquisition program (Labtech Notebook, Version 9.0, Laboratory Technologies Corp., FL, USA) where it was sampled at $800 \mathrm{~Hz}$. Heart rate was determined from the ECG trace by counting the time between $R-R$ peaks (AcqKnowledge V. 3.7, Biopac Systems Inc., CA, USA).

\section{DIVE TRIALS}

The rat was placed in the restraining cage and the subcutaneous electrodes attached to the pre-amplifier. The animal was allowed to settle down from the handling for $5 \mathrm{~min}$ followed by a forced submersion using the same approach as during the training sessions. The water temperature during all forced submersions was maintained around $30^{\circ} \mathrm{C}\left( \pm 1.0^{\circ} \mathrm{C}\right)$ to reduce thermal stress due to cold water immersion (Mcculloch and Panneton, 2003). The dive duration was standardized to $40 \mathrm{~s}$ unless the animal appeared distressed (struggle) or if the diving bradycardia was not maintained. In those instances the rat was immediately removed from the water. At completion of the dive, the animal was first dried with a towel and then placed in a cage with a heat lamp at one end, allowing the animal access to additional heat while air drying.

Each animal performed only one dive experiment per day, but repeated the experiment on three occasions separated by at least $24 \mathrm{~h}$ and at most 7 days. Out of six animals used for each strain, three repeated dives with successful heart rate recordings were obtained for five Buffalo, five Fischer, and six outbred Wistar rats. One Buffalo and one Fischer rat performed one successful experiment after which one ECG electrode broke off. The data from these rats are included in Table 1 but the number of successful trials was only 16 for the inbred as compared with 18 for the outbred strains.

\section{DATA ASSESSMENT AND STATISTICAL ANALYSIS}

Heart rate data were split up and averaged into dive time bins of $5 \mathrm{~s}$. The average heart rate $30 \mathrm{~s}$ before the start of the dive was considered the pre-dive period. The average heart rate immediately following a dive and for the next $30 \mathrm{~s}$ was considered the post-dive period.

Mixed models regression using a compound symmetry covariance structure to deal with the correlation within rats (Littell et al., 1998) was used to determine the best predictive model for the relationship between heart rate (dependent variable) and four experimental variables[dive period (pre-dive, dive, post-dive), rat strain, body mass, dive time bin] as independent fixed covariates. Statistical analyses were performed using the nlme package in $\mathrm{R}$ (A Language and Environment for Statistical Computing, R Foundation for Statistical Computing, v.2.5.1, 2007). Animal ID was included as a random effect, which accounts for the correlation between repeated measurements on the same rat.

Forward and backward stepwise techniques were used to search for the best model. The likelihood ratio test was used to determine significance of parameters between nested models. In this test, significance is defined by increases in the log-likelihood (LL) values of the models (i.e., significantly smaller negative LL values). Acceptance of significance was set at $P<0.05$, and $0.05<P<0.1$ was considered to be important enough to warrant investigation or consideration. All values are reported as means \pm SD unless otherwise stated.

\section{HERITABILITY}

Measuring the variability of a trait within and between individuals is useful to assess the genetic contribution, or heritability, of the trait of interest (Spicer and Gaston, 1999). The total variation of a physiological trait $\left(V_{\mathrm{t}}\right)$, or phenotype, is the sum of the genetic variation and environmental factors. Genetic variation is caused by differences among genes ( $V_{\mathrm{a}}$, additive variation) and interaction between genes (non-additive variation). Narrow-sense heritability $\left(h^{2}\right)$ is a useful measure to predict how animals will respond to natural selection and is the ratio between the additive genetic variation and the total variation $\left(h^{2}=V_{\mathrm{a}} / V_{\mathrm{t}}\right)$. If a trait has a high narrow-sense heritability, selection can alter that trait. Repeatability (R), or the intra-class coefficient (Sokal, 1981) is a simple and useful measure to assess the $h^{2}$ of the trait of interest (Dohm, 2002). $\mathrm{R}$ is a measure of the proportion of variance between individuals to the summed variance both between and within individuals (Falconer and Mackay, 1996) and is usually expressed as a percentage. Consequently, a high $\mathrm{R}$ represents a trait where most of the variation is partitioned between individuals and is likely to respond to natural selection (Dohm, 2002). One strategy to study complex physiological traits is to reduce the genetic variation between animals by studying inbred strains (Tankersley et al., 1994, 1997). Thus, we aimed to screen different strains of inbred rats and measure the heart rate responses during forced diving. We compared the responses against an outbred strain, which enabled us to estimate the contribution of genetic and environmental variability.

\section{RESULTS}

\section{BODY MASS}

There were significant differences in the mean body mass $( \pm S D)$ between strains $(P<0.05$, mixed effects model, Table 1), and both Buffalo and outbred rats weighed more than the Fischer strain during the dive trials (Table 1).

\section{DIVE TRAINING}

Initially, most rats struggled during the forced diving but at the end of the training period most appeared calm during the submergence. In addition, most rats entered the restraining device with little difficulty, and they appeared calmer in a cage with minimal room for movement.

\section{DIVE DURATION}

The forced submersion ended before the $40 \mathrm{~s}$ pre-determined dive duration in 8 out of 18 dives for the outbred rats as the heart rate increased (Figure 1). The increase in heart rate coincided with increasing struggle. For this reason, the dive duration in the outbred strain was significantly shorter from either of the inbred strains, where a dive ended prematurely only once for a Fischer rat $(P<0.05$, mixed effects model $)$. 
Table 1 | Total number of animals $(N)$ performing three dives separated by at least 1 day, mean $( \pm S D)$ body mass $\left(M_{b}\right)$, and mean resting heart rate $\left(f_{H}\right)$ immediately before the dive for a total of three repeated forced dives performed on different days. One Fischer and one Buffalo rat completed only one dive experiment and their data are included.

\begin{tabular}{|c|c|c|c|c|c|c|}
\hline Strain & $N$ & Mean $M_{\mathrm{b}}(\mathbf{g})$ & Resting $f_{\mathrm{H}}$ (beats $\min ^{-1}$ ) & Mean dive $f_{\mathrm{H}}$ (beats $\min ^{-1}$ ) & Post-dive $f_{H}$ (beats $\min ^{-1}$ ) & Mean dive duration (s) \\
\hline Buffalo & $5(15)$ & $205.3 \pm 14.2^{\mathrm{a}}$ & $395.0 \pm 15.6^{\dagger}$ & $92.8 \pm 12.8^{t b}$ & $400.9 \pm 31.5$ & $38.2 \pm 3.1^{b}$ \\
\hline
\end{tabular}

Superscripted letters indicate significant differences between groups, i.e., groups which are different (one way ANOVA followed by Bonferroni multiple comparison). ${ }^{+}$Variance significantly different from the outbred strain $\left(P<0.05, F\right.$-test, $F$-crit $\left.{ }_{(0.05,5,5)}=5.05\right)$.

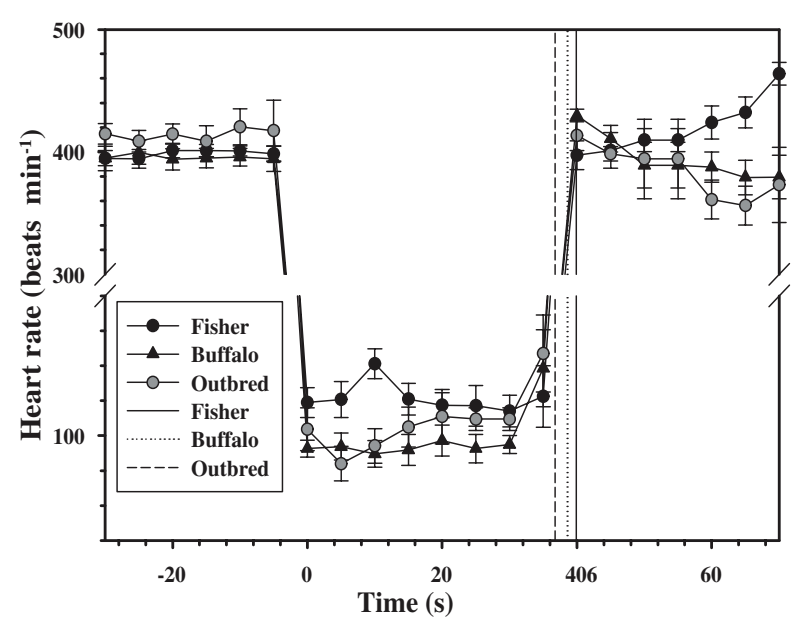

FIGURE 1 | Mean ( \pm 1 SD) heart rate every $5 \mathrm{~s}$ for two inbred (Fischer and Buffalo) and one outbred strain of rats ( $n=6$ rats in each strain), $30 \mathrm{~s}$ before, during, and $30 \mathrm{~s}$ after forced submergence. The mean is for a total of three repeated forced dives performed on different days. One Fischer and one Buffalo rat completed only one dive experiment which they lost their ECG electrodes, and their data are included. Solid and dotted vertical lines are the mean dive duration for each of the strains.

\section{HEART RATES}

Pre-dive, dive, or post-dive heart rates were not affected by variation in body mass either within $(P>0.05$ for all) or between strains $(P>0.1$, mixed effects model $)$.

There were no temporal changes in pre-dive resting heart rates during the $30 \mathrm{~s}$ before the dive $(P>0.1$, mixed effects model). In addition, the pre-dive heart rates did not differ between inbred or outbred strains $(P>0.1$, mixed effects model, Table 1$)$. However, the variance in heart rate during the resting period before the dive was higher in the outbred strain as compared with the inbred strains $\left(P<0.05\right.$, Fischer-Outbred: $F_{(0.05,5,5)}=5.79$, Buffalo-Outbred: $\left.F_{(0.05,5,5)}=6.49\right)$, but not different between inbred strains $\left(P>0.1\right.$, Table $\left.1, F_{(0.05,5,5)}=1.14\right)$.

For all rats for which the data were retained in the analysis, there was an immediate diving bradycardia (within 1-2 s) as the animal was submerged that persisted until the rat surfaced (Figure 1). The bradycardia was maintained throughout submergence, and the mean heart rate during each $5 \mathrm{~s}$ interval was constant for all strains $(P>0.4$, mixed effects model). There were significant differences in the diving heart rate between the Fischer and Buffalo strains $(P<0.05$, mixed effects model followed by Bonferroni multiple comparison; Figure 1), but not between inbred and outbred strains (Table 1).
The heart rate upon re-surfacing returned to pre-dive values within $5 \mathrm{~s}$ for all strains and remained constant for the next $30 \mathrm{~s}$. However, there was a trend toward a post-dive tachycardia in the Fischer strain starting $25 \mathrm{~s}$ after surfacing (Figure 1; $P<0.1$, mixed effects model). There were no differences in mean post-dive heart rate between strains over the $30 \mathrm{~s}$ following the dive $(P>0.1$; Table 1).

Between the inbred strains only $\mathrm{R}$, and its associated standard error of the mean (Sokal, 1981; Becker, 1984), was $0.99 \pm 0.005$ for diving $\mathrm{f}_{\mathrm{H}}$. Within strains, $\mathrm{R}$ for $\mathrm{f}_{\mathrm{H}}$ during diving was of $0.93 \pm 0.05$ for the outbred, $0.84 \pm 0.16$ for Buffalo, and $0.80 \pm 0.12$ for Fischer rats.

\section{DISCUSSION}

We measured the heart rate response during forced diving. Our data are the first to suggest a genetic component of the universal diving bradycardia and we have shown that genetically distinct populations of rats demonstrate divergent heart rate responses during diving. The results also suggest that the trait is heritable and could respond to natural selection. While future analysis of the heart rate variability between strains may indicate a mechanism behind these differences, the current analysis cannot assess whether the divergent responses between strains are caused by 
differences in neural control (sympathetic vs. parasympathetic control), or variation in endocrine response. In addition, the data presented here cannot determine the genetic components that control these differences.

\section{HEART RATE CHANGES DURING FORCED VS. VOLUNTARY DIVES}

The data presented in this study are limited to the heart rate response during forced submergence. As such, this represents a maximum response to an acute situation, such as asphyxiation or stroke in a human, or predator avoidance in a freely diving animal (Fedak et al., 1988). In unrestrained, trained, or free-diving marine mammals, on the other hand, the response is more variable and generally not as severe (Kooyman and Campbell, 1972; Hill et al., 1987; Thompson and Fedak, 1993; Ponganis et al., 1997; Hindell and Lea, 1998). It has been suggested that the primary role of diving bradycardia is to regulate the degree of hypoxia in skeletal muscle so that blood and muscle oxygen stores can be used more efficiently (Davis and Kanatous, 1999; Davis et al., 2004; Fahlman et al., 2009). In this scenario, the heart rate changes during voluntary diving would serve as a mechanism to manage the available $\mathrm{O}_{2}$ within the planned dive and to maximize the aerobic dive limit (Kooyman, 1985; Davis and Kanatous, 1999; Fahlman et al., 2009). Still, the extremely low heart rates seen during forced dives are rarely seen in freely diving animals at sea. Heart rates during voluntary dives include confounding variables, such as variation in exercise level (Williams et al., 1991, 2004; Signore and Jones, 1996) or dive duration (Ponganis et al., 1997), and we therefore opted to use forced diving experiments in this study. The effect of habituation of forced diving has been variable in different species and studies (Gabbott and Jones, 1987; Jobsis et al., 2001; Mcculloch et al., 2010b; Panneton et al., 2010a,b). For example, repeated forced head submersions abolished the diving bradycardia in the duck (Gabbott and Jones, 1987) and reduced the magnitude of the response in three out of four harbor seals (Jobsis et al., 2001). In the rat, on the other hand, habituation does not appear to affect the magnitude of the diving bradycardia (Mcculloch et al., 2010b; Panneton et al., 2010a), but the mean arterial blood pressure decreases in habituated rats that dive $>10 \mathrm{~s}$ (Mcculloch et al., 2010b; Panneton et al., 2010a). In the current study, the heart rate in the outbred strain decreased within 1-2 s after submersion by $75 \%$, which is similar to that observed in outbred Sprague-Dawley rats of similar size (Mcculloch et al., 2010b; Panneton et al., 2010a). However, in the current study the dive ended before the pre-determined dive duration in eight out of the 18 dives, and this was associated with increasing heart rates as the rats began to struggle (Figure 1). In the inbred strains, the mean diving bradycardia was greater in the Buffalo strain as compared with the Fischer strain, with the outbred group being somewhere in between (Figure 1). In addition, the variation in the heart rate between individuals was much less varied both before and during the dive in the inbred strains as compared with the outbred rats (Table 1).

Unlike other dive studies in rats (Mcculloch et al., 2010b; Panneton et al., 2010a), we focused on the heart rate responses during forced diving. The dive response consists of numerous reflexes that result in a reduction in the heart rate and peripheral vasoconstriction (Kooyman, 1989; Butler and Jones, 1997). Studies in forced and voluntary diving in muskrats have shown that the diving bradycardia occurs independently of the peripheral vasoconstriction (Signore and Jones, 1995), and that the parasympathetic activity predominates the heart rate response while sympathetic influence has minimal effect (Signore and Jones, 1995, 1996). This "accentuated antagonism" therefore results in parasympathetic dominance of the heart rate response, despite considerable vagal stimulation. Whether the parasympathetic tone dominates the heart rate response in diving rats is debatable, but accentuated antagonism has been reported in diving muskrats (Signore and Jones, 1995, 1996), harbor seals (Elliott et al., 2002), and the lesser scaup (Mcphail and Jones, 1999). It was also considered a plausible mechanism to explain the heart rate responses in a previous study in forced diving rats (Mcculloch et al., 2010b). While forced diving appears to be more stressful and significantly varies the sympathetically mediated vasoconstriction as compared with voluntary dives, the diving bradycardia does not vary between modes of diving (Mcculloch et al., 2010b; Panneton et al., 2010a). Because the heart rate response, unlike the peripheral vasoconstriction, appears to be conserved and vary the least in both voluntary and forced diving rats, it was the target trait in the current study.

\section{VARIABILITY OF THE HEART RATE RESPONSE AND HERITABILITY}

The heart rate variation highlights something fundamental in physiological research. The within- and between-animal variability of the cardiac responses to diving is poorly understood. Both theoretical (Davis and Kanatous, 1999; Davis et al., 2004; Fahlman et al., 2009) and experimental (Ponganis et al., 1997) studies have suggested that the heart rate response is crucial to extend the aerobic dive limit, and is most likely influenced by genetic as well as multiple physiological factors. Therefore, it is not surprising that most studies have reported considerable variability within and between individual animals. To our knowledge, no other study has attempted to partition the within and between subject variability in the heart rate response to diving and most other studies report mean values (Panneton et al., 2010a). The average heart rate may not be representative of an individual's or species sensitivity or physiological plasticity to submergence, and may be particularly misleading, especially when the variable in question exhibits high between-individual variation (Dohm, 2002; Terblanche et al., 2004). Therefore, we suggest that studies should perform rigorous partitioning of sources of variation of the reflexes that make up the dive response. We suggest that $\mathrm{R}$ is a useful measure as it is an estimate of the variation between in relation to that within individuals (Sokal, 1981; Falconer and Mackay, 1996). In addition, the R of a trait is an estimate of the narrow-sense heritability and may represent the upper limit for its evolutionary significance (Dohm, 2002), and identification of variables with a high $\mathrm{R}$ are those most likely to respond to natural selection. While the mean and its associated error may give some important information, it cannot be used to answer questions about evolutionary importance (Terblanche et al., 2004, 2005).

While our data are limited, it provides a basic understanding about the raw material allowing this physiological trait to change by natural selection. Differential reproduction and survival are prerequisites for natural selection. For a physiological trait to be 
responsive to natural selection it must show (1) a relationship between the trait and varying fitness, (2) heritability, and (3) consistent variation between individuals (Endler, 1986). In humans, a more marked diving bradycardia conserves $\mathrm{O}_{2}$ and allows for longer duration breath-holds (Lindholm et al., 1999). In animals, a decrease in average heart rate allows for increasing time submerged (Kooyman, 1985; Fedak et al., 1988). This extends the time available for prey acquisition, which in turn increase survival. If the diving bradycardia responds to natural selection, we would expect $\mathrm{R}$ to be higher in the outbred strain and between inbred strains, but close to 0 within inbred strains if the genetic variation had considerable influence on the trait as $V_{\mathrm{g}} \sim 0$. R was indeed high in the outbred strain but surprisingly high also within both inbred strains. This suggests an arrangement of genes that interact to alter the trait within a narrow margin, or a trait where the variation due to the environment is more important than the genetic effects. Despite this, $\mathrm{R}$ was high both within and between strains suggesting that the trait is able to respond to natural selection.

\section{CONCLUSION}

Our data are the first to suggest a genetic component of the heart rate response during diving, and we have shown that genetically distinct populations of rats demonstrate divergent responses.

\section{REFERENCES}

Becker, W. A. (1984). Manual of Quantitative Genetics. Washington: Academic Enterprises.

Butler, P. J., and Jones, D. R. (1997). Physiology of diving of birds and mammals. Physiol. Rev. 77, 837-899.

Davis, R. W., and Kanatous, S. B. (1999). Convective oxygen transport and tissue oxygen consumption in Weddell seals during aerobic dives. J. Exp. Biol. 202, 1091-1113.

Davis, R. W., Polasek, L., Watson, R., Fuson, A., Williams, T. M., and Kanatous, S. B. (2004). The diving paradox: new insights into the role of the dive response in air-breathing vertebrates. Comp. Biochem. Physiol. Part A Mol. Integr. Physiol. 138, 263-268.

Dohm, M. R. (2002). Repeatability estimates do not always set an upper limit to heritability. Funct. Ecol. 16, 273-280.

Elliott, N. M., Andrews, R. D., and Jones, D. R. (2002). Pharmacological blockade of the dive response: effects on heart rate and diving behaviour in the harbour seal (Phoca vitulina). J. Exp. Biol. 205, 3757-3765.

Endler, J. A. (1986). Natural Selection in the Wild. New Jersey: Princeton University Press.

Fahlman, A., Hooker, S. K., Szowka, A., Bostrom, B. L., and Jones, D. R. (2009). Estimating the effect of lung collapse and pulmonary shunt on gas exchange during breath-hold diving: The Scholander and Kooyman legacy. Respir. Physiol. Neurobiol. 165, 28-39.
Falconer, D. S., and Mackay, T. F. C. (1996). Introduction to Quantitative Genetics. Harlow: Pearson Prentice Hall.

Fedak, M. A., Pullen, M. R., and Kanwisher, J. (1988). Circulatory responses of seals to periodic breathing: heart rate and breathing during exercise and diving in the laboratory and open sea. Can. J. Zool. 66, 53-60. Gabbott, G. R. J., and Jones, D. R. (1987). Habituation of the cardiac response to involuntary diving in diving and dabbling ducks. J. Exp. Biol. 131, 403-415.

Gordon, C. J., Lee, K. L., Chen, T. L., Killough, P., and Ali, J. S. (1991). Dynamics of behavioral thermoregulation in the rat. Am. J. Physiol. 261, R705-R711.

Haldane, J. B. S., and Waddington, C. H. (1931). Inbreeding and linkage. Genetics 16, 357-374. G. C., Schuette, A. H., Elliott, R. L., Guppy, M., Hochachka, P. W., Qvist, J., Falke, K. J., and Zapol, W. M. (1987). Heart rate and body temperature during free diving of Weddell seals. Am. J. Physiol. 253, 344-351.

Hindell, M. A., and Lea, M. (1998). Heart rate, swimming speed, and estimated oxygen consumption of a free-ranging southern elephant seal. Physiol. Zool. 71, 74-84.

Jobsis, P. D., Ponganis, P. J., and Kooyman, G. L. (2001). Effects of training on forced submersion responses
Hill, R. D., Schneider, R. C., Liggins,

Heart rate variability in inbred rats was significantly less than in the outbred strain both before and while diving. The differences in heart rate variability between inbred and outbred rat strains show that this trait is genetically controlled and a portion of the variability in diving bradycardia is genetic. However, our data do not tell us anything about which or how many genes are involved. It has been proposed that the control system regulating and modulating heart rate changes is complex (Mottishaw et al., 1999). Thus, understanding the genetic mechanism behind these differences will be complicated. Linkage analysis has shown great success in detailing the ventilatory response to hypoxia in mice and a similar approach could be used here (Tankersley et al., 1994, 1997).

\section{ACKNOWLEDGMENTS}

We would like to thank Arthur Vanderhorst and Sam Gopaul for their assistance in maintaining the animals. This research was supported by NSERC Discovery Grants to David R. Jones. All experiments were done in accordance with CCAC guidelines under an Animal Care Certificate issued by UBC. A special thanks to Sascha Hooker and Susan Kayar for helpful comments early versions of this paper. We are also grateful for the thoughtful comments from two referees that helped improve the paper.

in harbor seals. J. Exp. Biol. 204, 3877-3885.

Kooyman, G. L. (1985). Physiology without restraint in diving mammals. Science 1, 166-178.

Kooyman, G. L. (1989). Diverse Divers; Physiology and Behavior. New York: Springer-Verlag.

Kooyman, G. L., and Campbell, W. B. (1972). Heart rates in freely diving Weddell Seals, Leptonychotes weddellii. Comp. Biochem. Physiol. A Comp. Physiol. 43, 31-36.

Lin, Y. C., and Baker, G. (1975). Cardiac output and its distribution during diving in the rat. Am. J. Physiol. 228, 733-737.

Lindholm, P., Sundblad, P., and Linnarsson, D. (1999). Oxygen-conserving effects of apnea in exercising men. $J$. Appl. Physiol. 87, 2122-2127.

Littell, R. C., Henry, P. R., and Ammerman, C. B. (1998). Statistical analysis of repeated measures data using SAS procedures. J. Anim. Sci. 76, 1216-1231.

Lundgren, C. E. G., and Miller, J. N. (1999). The Lung at Depth. New York: Dekker.

Manley, L. (1990). Apnoeic heart rate responses in humans. A review. Sports Med. 9, 286-310.

Mcculloch, P. F., Dinovo, K. M., and Connolly, T. M. (2010a). The cardiovascular and endocrine responses to voluntary and forced diving in trained and untrained rats. Am. J. Physiol. Regul. Integr. Comp. Physiol. 298, R224-R234.
Mcculloch, P. F., Dinovo, K. M., and Connolly, T. M. (2010b). The cardiovascular and endocrine responses to voluntary and forced diving in trained and untrained rats. Am. J. Physiol. Regul. Integr. Comp. Physiol. 298, 224-234.

Mcculloch, P. F., and Panneton, W. M. (2003). Activation of brainstem catecholaminergic neurons during voluntary diving in rats. Brain Res. 984 , 42-53.

Mcphail, L. T., and Jones, D. R. (1999). The autonomic nervous control of heart rate in ducks during voluntary diving. Physiol. Biochem. Zool. 72, 164-169.

Mottishaw, P. D., Thornton, S. J., and Hochachka, P. W. (1999). The diving response mechanism and its surprising evolutionary path in seals and sea lions. Am. Zool. 39, 434-450.

Ollenberger, G. P., Matte, G., Wilkinson, A. A., and West, N. H. (1998). Relative distribution of blood flow in rats during surface and submerged swimming. Comp. Biochem. Physiol. Part A Mol. Integr. Physiol. 119, 271-277.

Panneton, W. M., Gan, Q., and Dahms, T. E. (2010a). Cardiorespiratory and neural consequences of rats brought past their aerobic dive limit. J. Appl. Physiol. 109, 1256-1269.

Panneton, W. M., Gan, Q., and Juric, R. (2010b). The rat: a laboratory model for studies of the diving response. $J$. Appl. Physiol. 108, 811-820. 
Ponganis, P. J., Kooyman, G. L., Winter, L. M., and Starke, L. N. (1997). Heart rate and plasma lactate responses during submerged swimming and trained diving in California sea lions, Zalophus californianus. J. Comp. Physiol. B Biochem. Syst. Environ. Physiol. 167, 9-16.

Scholander, P. F. (1963). The master switch of life. Sci. Am. 209, 92-106.

Signore, P. E., and Jones, D. R. (1995). Effect of pharmacological blockade on cardiovascularresponses to voluntary and forced diving in muskrats. J. Exp. Biol. 198, 2307-2315.

Signore, P. E., and Jones, D. R. (1996). Autonomic nervous control of heart rate in muskrats during exercise in air and under water. J. Exp. Biol. 199, 1563-1568.

Sokal, R. R. (1981). Biometry, the Principles and Practice of Statistics in Biological Research. San Francisco: Freeman.
Spicer, J. I., and Gaston, K. J. (1999). Physiological Diversity and its Ecological Implications. Oxford: Blackwell.

Tankersley, C. G., Fitzgerald, R. S., and Kleeberger, S. R. (1994). Differential control of ventilation among inbred strains of mice. Am. J. Physiol. 267, R1371-R1377.

Tankersley, C. G., Fitzgerald, R. S., Levitt, R. C., Mitzner, W. A., Ewart, S. L., and Kleeberger, S. R. (1997). Genetic control of differential baseline breathing pattern. J. Appl. Physiol. 82, 874-881.

Terblanche, J., Fahlman, A., Myburgh, K. H., and Jackson, S. (2004). Measurement reliability of highly variable physiological responses to experimentally manipulated gas fractions. Physiol. Meas. 25, 1189-1197.

Terblanche, J. S., Tolley, K. A., Fahlman, A., Myburgh, K. H., and Jackson, S. (2005). The acute hypoxic ventilatory response: testing the adaptive significance in human populations. Comp. Biochem. Physiol. Part A Mol. Integr. Physiol. 140, 349-362.

Thompson, D., and Fedak, M. A. (1993). Cardiac responses of grey seals during diving at sea. J. Exp. Biol. 174.

Williams, T. M., Fuiman, L. A., Horning, M., and Davis, R. W. (2004). The cost of foraging by a marine predator, the Weddell seal Leptonychotes weddellii: pricing by the stroke. J. Exp. Biol. 207, 973-982.

Williams, T. M., Kooyman, G. L., and Croll, D. A. (1991). The effect of submergence on heart-rate and oxygenconsumption of swimming seals and sea lions. J. Comp. Physiol. B Biochem. Syst. Environ. Physiol. 160, 637-644.

Conflict of Interest Statement: The authors declare that the research was conducted in the absence of any commercial or financial relationships that could be construed as a potential conflict of interest.

Received: 27 May 2011; accepted: 31 August 2011; published online: 20 September 2011.

Citation: Fahlman A, Bostrom BL, Dillon KH and Jones DR (2011) The genetic component of the forced diving bradycardia response in mammals. Front. Physio. 2:63. doi: 10.3389/fphys.2011.00063

This article was submitted to Frontiers in Aquatic Physiology, a specialty of Frontiers in Physiology.

Copyright (c) 2011 Fahlman, Bostrom, Dillon and Jones. This is an open-access article subject to a non-exclusive license between the authors and Frontiers Media $S A$, which permits use, distribution and reproduction in other forums, provided the original authors and source are credited and other Frontiers conditions are complied with. 